\title{
Ecological Risk Assessment of Phthalate Esters (DBP and DEHP) in Surface Water of China
}

\author{
Fuhong Sun, Yanru Tao, Di Shi, Jiwei Yang, Huixian Li, Yuan Wei and Hailei Su*
}

State Key Laboratory of Environmental Criteria and Risk Assessment, Chinese Research Academy of Environmental Sciences, Beijing, China

As a new type of pollutant, phthalate esters (PAEs) are common organic compounds in industrial production and daily life, which are widely detected in surface water environment. Among them, dibutyl phthalate (DBP) and bis (2-ethylhexyl) phthalate (DEHP) have attracted much attention due to their harmful effects on aquatic life such as endocrine disrupting effects. In this study, the toxicity data of DBP and DEHP were collected and screened through literature research, and their water quality criteria (WQC) for protecting aquatic life were derived by the species sensitivity distribution method. In addition, the

OPEN ACCESS

Edited by:

Shuwen Yan,

Fudan University, China

Reviewed by:

Shuying Li,

Zhejiang University, China Agnieszka Klimkowicz-Pawlas, Institute of Soil Science and Plant

Cultivation, Poland

Ai Zhang,

Donghua University, China

*Correspondence:

Hailei Su

suhailei666@163.com

Specialty section:

This article was submitted to

Toxicology, Pollution and the

Environment,

a section of the journal

Frontiers in Environmental Science

Received: 15 May 2021

Accepted: 08 July 2021

Published: 12 August 2021

Citation:

Sun F, Tao Y, Shi D, Yang J, Li H, Wei Y and Su H (2021) Ecological Risk Assessment of Phthalate Esters (DBP and $D E H P)$ in Surface Water of China.

Front. Environ. Sci. 9:710125.

doi: 10.3389/fenvs.2021.710125 distributions of DBP and DEHP in surface water environment of China were analyzed and their ecological risk levels to aquatic life in six regions were evaluated by hazard quotients (HQs) and probabilistic approaches. The result revealed that the chronic WQC of DBP is $12.9 \mu \mathrm{g} / \mathrm{L}$ (criteria continuous concentration, CCC) and acute WQC is $162.9 \mu \mathrm{g} / \mathrm{L}$ (criteria maximum concentration, $\mathrm{CMC}$ ) and the chronic WQC of DEHP is $1.0 \mu \mathrm{g} / \mathrm{L}(\mathrm{CCC})$ and acute WQC is $71.8 \mu \mathrm{g} / \mathrm{L}(\mathrm{CMC})$. The ecological risk of DBP and DEHP in North China and Yangtze River is relatively higher than other regions, which may have harmful effects on the aquatic environments. So, it is necessary to strengthen the water quality management. The results could provide scientific basis for ecological risk management of DBP and DEHP.

Keywords: phthalate esters, water quality criteria, aquatic life, risk assessment, environmental management

\section{INTRODUCTION}

Phthalate esters (PAEs) are common plasticizers, which are mainly used to improve the flexibility of plastic products for processing (Howdeshell et al., 2008; Abdel Daiem et al., 2012). The sources of phthalates in the environment are mainly anthropogenic activities and the annual output of PAEs in China is about 400,000 tons (Pei et al., 2013; Wang et al., 2013). PAEs can enter the water body directly and indirectly. The direct ways include the discharge of industrial waste water containing PAEs and the surface runoff of rainwater after washing agricultural plastic film, insect repellent, plastic garbage, etc. (Huang et al., 2020). Besides, humic acid produced by the decay of animals, plants, microorganisms, and their wastes in the water has a large association constant with PAEs, leading to the presence of PAEs in the water environment (Cao et al., 2018). The indirect way is that these compounds are first discharged into the atmosphere, and then transferred into the water environment through dry deposition or rainwater leaching. As a kind of environmental endocrine disruptors, PAEs have estrogen-like effect. PAEs can combine with hormone receptors in the body, causing nervous system disorders, endocrine disorders, and immune decline, resulting in reproductive and developmental damage and other health problems. In addition, some PAEs are bioaccumulative and can be accumulated in organisms, accordingly causing serious harm to high 
trophic organisms (Sun et al., 2016). In recent years, PAEs have attracted much attention due to their harmful effects on human health and ecological environment.

PAEs have adverse effects on the growth and development of aquatic organisms, with less acute toxicity and more chronic toxicity. Most of the PAEs have estrogen effect, which can interfere with the secretion and synthesis of animal sex hormones, thus affecting biological growth and development (Shi et al., 2012; Zhai et al., 2014). The 96-h lethal concentration to 50 percent of the population (LC50) values of DBP for six aquatic organisms was determined by Mayer and Sanders, ranging from 0.73 to more than $10 \mathrm{mg} / \mathrm{L}$ (Mayer and Sanders, 1973). Zhao et al. (2014) studied the toxic effect of DEHP on Pinctada martensii and found that the lowest observed effect concentration (LOEC) was less than $0.5 \mathrm{mg} / \mathrm{L}$. Studies showed that DEHP also had harmful impacts on fish growth (Defoe et al., 1990). The ecological risks of PAEs in the Chinese surface water were studied and results showed that DBP and DEHP were the main compounds in PAEs and had higher ecological risks to aquatic organisms (Gao et al., 2019; Guo et al., 2019). Besides, as a common environmental endocrine disruptors, PAEs can enter the human body through respiration, digestive tract, and skin contact (Song et al., 2016) and cause adverse effects on many aspects of human health (Zhang and Shu, 2005; Giribabu and Reddy, 2016).

More than 20 kinds of PAEs have been detected in environmental samples, including dimethyl phthalate (DMP), diethyl phthalate (DEP), dibutyl phthalate (DBP), dioctyl phthalate (DOP), bis (2-ethlyhexyl) phthalate (DEHP), and butyl benzyl phthalate (BBP), which are widely distributed in air, water, and soil (Sha et al., 2006; Liu et al., 2010). Among them, DBP and DEHP are two typical PAEs, which have been listed as priority pollutants and toxics release inventory (TRI) in the United States due to their adverse effects on environmental and human health (USEPA, 1997; Howdeshell et al., 2008; Lyche et al., 2009; USEPA, 2012). Several studies has been conducted to evaluate the ecological risk of DBP and DEHP in regional surface waters in China and indicated that research work in this field should be strengthened (Hu et al., 2012; Wang et al., 2017). The water quality criteria of PAEs was studied by EPA in 1980 and the acute and chronic toxicity concentrations of PAEs to freshwater aquatic organisms were low to 940 and $3 \mu \mathrm{g} / \mathrm{L}$, respectively (USEPA, 1980). Both surface water environmental quality standard (GB 3838-2002) and drinking water quality standard (GB 5749-2006) of China stipulate the standard values of DBP and DEHP for drinking water which are 3 and $8 \mu \mathrm{g} / \mathrm{L}$, respectively. It is necessary to derive the WQCs of China to provide scientific protection for aquatic ecological health $(\mathrm{Wu}$ et al., 2010).

Till now, the WQCs of DBP and DEHP for the protection of aquatic organisms in China have not been derived. Several studies on the ecological risk assessment of used the predicted no effect concentration (PNEC) calculated for specific sites (Chen et al., 2019; Gao et al., 2019). Therefore, there is lack of scientific basis for risk assessment and environmental management of water ecology in China. According to the guidelines for deriving water quality criteria for aquatic life protection in China, the water quality criteria of DBP and DEHP for protection of aquatic life in China were derived by collecting and screening toxicity data of aquatic species, and the environmental risk levels of DBP and DEHP in China's surface water were evaluated. The study aims to provide the basis for water quality criteria, risk assessment, and environmental management of PAEs in China.

\section{MATERIALS AND METHODS}

\section{Toxicity Data Collection and Water Quality Criteria Derivation}

The acute and chronic toxicity data of DBP and DEHP to aquatic organisms are collected mainly from the ECOTOX database of EPA (http://www.epa.gov/ecotox/) and related published literature. The toxicity data of these two substances to aquatic species in China were screened (Supplementary Tables 1-4). Among them, acute data mainly includes LC50 or 50\% of effective concentration (EC50), chronic data mainly include the no observed effect concentration (NOEC) or LOEC. Aquatic organisms screened in this study mainly include algae, invertebrates (crustaceans, molluscs, insects, and other invertebrates), vertebrates (fish and amphibians), aquatic plants, etc. When more than one toxicity data can be obtained for each species, the geometric mean value is taken as the final toxicity value. The data screening and water quality criteria derivation were carried out according to the "technical guidelines for the development of freshwater aquatic water quality criteria” (HJ 831-2017) issued by China. The species sensitivity distribution (SSD) method is used to calculate the water quality criteria using the obtained toxicity data. The SSD was fitted using the ChinaWQC software and the hazardous concentration (HC) of DBP and DEHP were calculated. $\mathrm{HC}_{5}$ refers to concentrations under which the less than $5 \%$ of species are affected, that is to say, $95 \%$ of the species can be protected from toxicity. Finally, the obtained $\mathrm{HC}_{5}$ is divided by factor two to obtain the water quality criteria value.

\section{Exposure Data Collection and Ecological Risk Assessment}

The concentrations of DBP and DEHP in surface water of China were obtained through literature research (Supplementary Table 5). Exposure data were divided into six typical regions of China. These six regions are geographic regions and divided mainly based on the sapling sites of the exposure data. The ecological risks of DBP and DEHP in China's surface water environments were assessed according to the water quality criteria derived in this study. The hazard quotients (HQs) and probabilistic approaches were used to evaluate the risks of DBP and DEHP. HQ is the quotient of the environmental concentration divided by the derived WQC. If HQ values exceed 1.0, the potential risk exists. First, according to the calculated WQCs and the environmental concentrations (maximum, minimum, and average) in each region, the HQ method was used to evaluate the ecological risk. Then, according to the selected acute and chronic toxicity data and the concentrations (average value) in surface water, the 
TABLE 1 | Summary of toxicity data and WQCs of DBP and DEHP to aquatic life.

\begin{tabular}{|c|c|c|c|c|c|c|c|c|c|c|c|c|c|}
\hline \multirow[t]{2}{*}{ Chemicals } & \multirow{2}{*}{$\begin{array}{l}\text { Acute/ } \\
\text { chronic }\end{array}$} & \multirow[t]{2}{*}{ Fishes } & \multirow[t]{2}{*}{ Invertebrates } & \multirow[t]{2}{*}{ Amphibians } & \multirow[t]{2}{*}{ Algae } & \multirow{2}{*}{$\begin{array}{c}\text { Aquatic } \\
\text { plants }\end{array}$} & \multicolumn{3}{|c|}{ Sum } & \multirow[t]{2}{*}{ Models } & \multirow[t]{2}{*}{$R^{2}$} & \multirow[t]{2}{*}{$\mathrm{HC}_{5}$} & \multirow{2}{*}{$\begin{array}{r}\text { WQC } \\
\text { ( } \mu \mathrm{g} / \mathrm{L})\end{array}$} \\
\hline & & & & & & & Phylum & Family & Species & & & & \\
\hline \multirow[t]{2}{*}{ DBP } & Acute & 12 & 5 & 1 & 1 & 0 & 4 & 14 & 19 & Normal & 0.97 & 325.8 & 162.9 \\
\hline & Chronic & 5 & 1 & 2 & 0 & 5 & 3 & 11 & 13 & Normal & 0.96 & 23.8 & 12.9 \\
\hline \multirow[t]{2}{*}{ DEHP } & Acute & 9 & 4 & 2 & 2 & 1 & 5 & 15 & 18 & Normal & 0.96 & 143.5 & 71.8 \\
\hline & Chronic & 6 & 4 & 0 & 1 & 0 & 4 & 8 & 11 & Normal & 0.94 & 2.0 & 1.0 \\
\hline
\end{tabular}

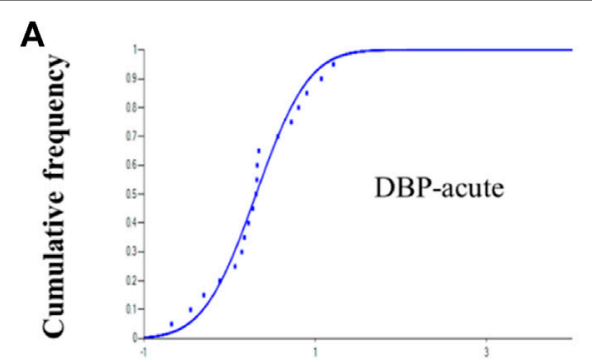

C

Log transformed concentrations

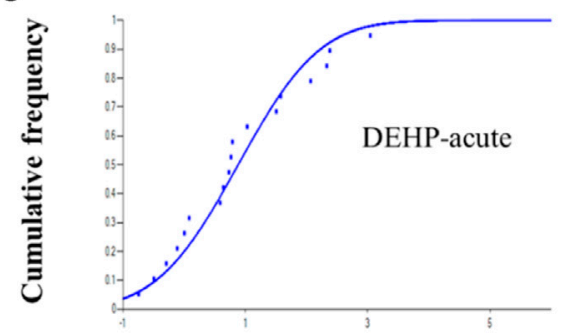

Log transformed concentrations

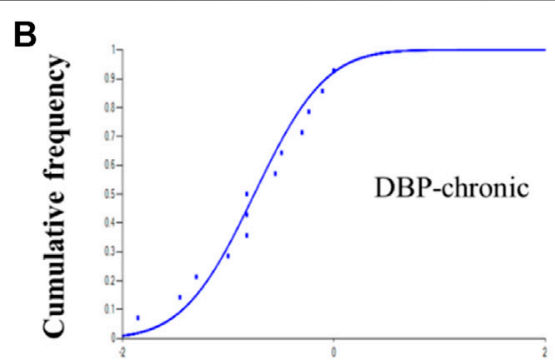

Log transformed concentrations

D

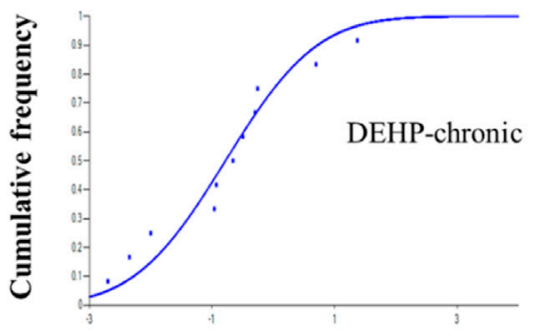

Log transformed concentrations

FIGURE 1 | SSD curves of DBP and DEHP (A. DBP acute data, B. DBP chronic data, C. DEHP acute data, and D. DEHP chronic data).

probabilistic approaches were used to evaluate the ecological risk (Qin et al., 2013; K.S et al., 2000). For the probabilistic method, the potential ecological risks were assessed by calculating the overlap area between the exposure and effect curves (Solomon et al., 2000). Log-transformed toxicity data were combined to produce effects concentration distribution curve and logtransformed exposure data are plotted on the same axes as the toxicity data. The overlap area between the curves indicates the risk probability. Software MATLAB (R2014a) was used to calculate the overlap area. Both log transformed toxicity data and $\log$ transformed exposure data follow the normal distribution (k-s test). The uncertainty in the ecological risk assessment mainly results from the toxicity data and exposes data.

\section{RESULTS AND DISCUSSION}

\section{Water Quality Criteria of Dibutyl Phthalate and Bis (2-Ethlyhexyl) Phthalate for Protection of Aquatic Life}

Besides toxicity data of DBP and DEHP from ECOTOX database, in order to derive the WQCs for the protection of aquatic organisms in China, relevant Chinese literature was reviewed to supplement the toxicity data of local species in China, including green algae (Chlorella vulgaris), zebra danio (Danio rerio), Chinese rare minnow (Gobiocypris rarus), and triangular bream (Megalobrame terminalis) (Li et al., 2007; He et al., 2010; Qin et al., 2011; Jia, 2013; Zhang et al., 2015; Liao et al., 2017). The acute and chronic toxicity data of DBP and DEHP are summarized in Table 1. Acute toxicity data of DBP to aquatic life ranged from 0.21 to $16.3 \mathrm{mg} / \mathrm{L}$, and chronic data from 0.014 to $1.0 \mathrm{mg} / \mathrm{L}$. For DEHP, acute data ranged from 0.18 to $1,106.2 \mathrm{mg} /$ $\mathrm{L}$, and chronic data from 0.002 to $23.6 \mathrm{mg} / \mathrm{L}$.

The available acute and chronic toxicity data of DBP and DEHP to aquatic organisms meets the data requirements of the guideline (HJ 831-2017). SSDs (as shown in Figure 1) were fitted by China WQC software and $\mathrm{HC}_{5}$ s were calculated based on the best fitting model. The derived WQCs for the DBP and DEHP were summarized in Table 1. Results showed that WQCs (both acute and chronic) of DEHP are much lower than those of DBP, indicating that DEHP is more toxic to aquatic life than DBP. The difference of aquatic toxicity between DBP and DEHP emphasizes the necessity to derive the WQCs, respectively, rather than using a uniform WQC for PAEs. According to the reviewed toxicity data, the algae are more sensitive to DBP and 

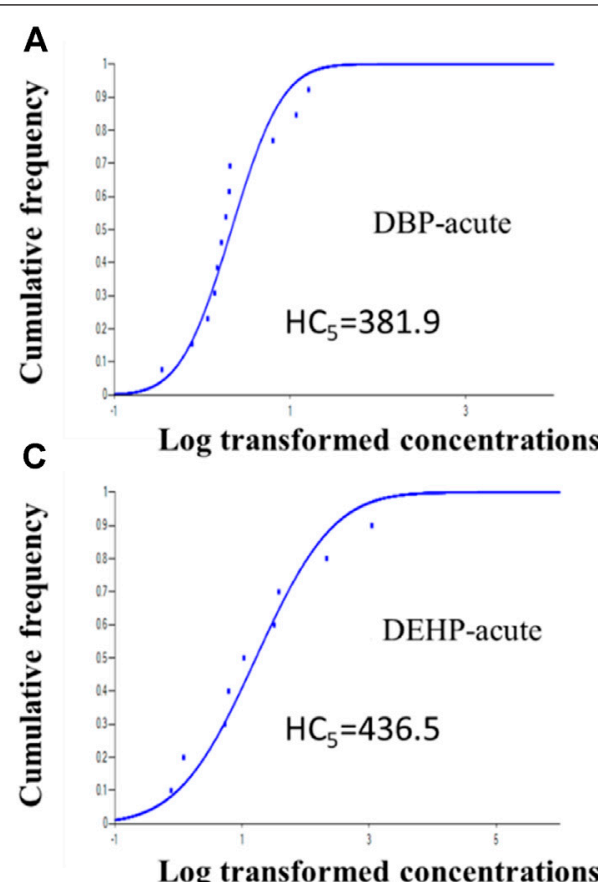

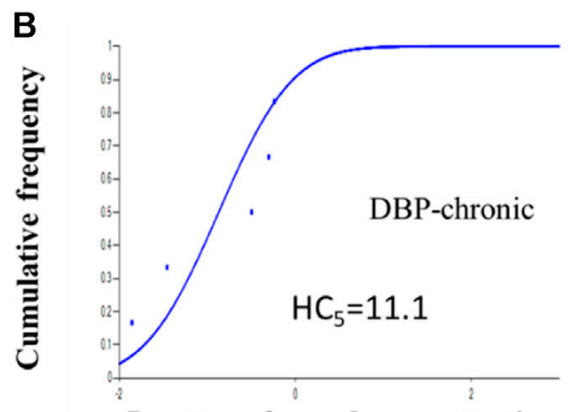

Log transformed concentrations

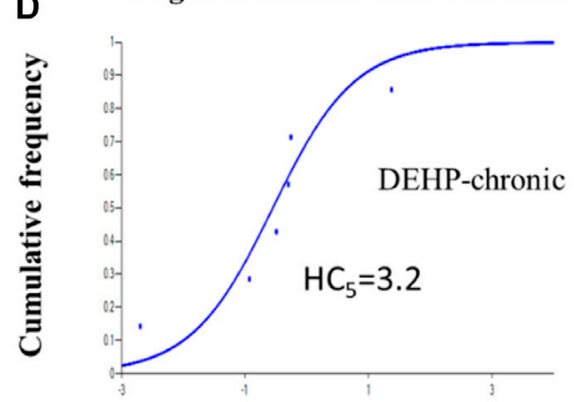

Log transformed concentrations

FIGURE 2 | SSD curves of DBP and DEHP for only fishes (A. DBP acute data, B. DBP chronic data, C. DEHP acute data, and D. DEHP chronic data).

DEHP than fishes, which are consistent with the reported literature (Hu et al., 2012).

Fish is one of the most important parts of aquatic ecosystem and fish protection is one of the most important objectives of water ecological protection. In order to analyze the toxicity of DBP and DEHP to fish species, SSDs were fitted using toxicity data only for fish and the corresponding $\mathrm{HC}_{5}$ s were calculated, as shown in Figure 2. For DBP, the acute $\mathrm{HC}_{5}$ of fishes is close to that of all aquatic organisms, while the chronic $\mathrm{HC}_{5}$ is much lower than that of all aquatic organisms, suggesting that fishes are more sensitive to the chronic effects than other aquatic species. However, for DEHP, the acute $\mathrm{HC}_{5}$ of fish is three times as much as that of all aquatic organisms, while the chronic $\mathrm{HC}_{5}$ of fishes is 1.5 times that of all aquatic organisms, indicating that fishes are not very sensitive to toxic effects of DEHP. The result is consistent with the reported literature (Mayer and Sanders, 1973; Hu et al., 2012), which means that protecting fish only does not necessarily fully protect aquatic ecosystems.

\section{Comparison and Analysis of Water Quality Criteria of Dibutyl Phthalate and Bis (2-Ethlyhexyl) Phthalate}

Studies on the WQCs of PAEs have been conducted by the United States, Canada, the European Union, and other countries and regions. Among them, the United States studied PAEs water quality criteria for protection of aquatic organisms in 1980 , with the acute WQC low to $940 \mu \mathrm{g} / \mathrm{L}$ and chronic WQC low to $3 \mu \mathrm{g} / \mathrm{L}$, respectively (USEPA, 1980). However, no WQCs for specific DBP or DEHP has been derived in the national recommended WQC from the USEPA till today. The European Union issued the environmental quality standard (EQS) of DEHP in 2013, and the annual average EQS (AAEQS) for surface waters was $1.3 \mu \mathrm{g} / \mathrm{L}(\mathrm{EU}, 2013)$. Canada issued long-term water quality criteria for DBP and DEHP for protection of aquatic organisms, which are 19 and $16 \mu \mathrm{g} / \mathrm{L}$, respectively (CCME, 2021). Both the Chinese surface water quality standard (GB3838-2002) and sanitary standard for drinking water (GB 5749-2006) have given the water quality standards for DBP and DEHP, with the same standard values of 3 and $8 \mu \mathrm{g} / \mathrm{L}$, respectively.

In this study, the acute WQCs of DBP and DEHP were 162.9 and $71.8 \mu \mathrm{g} / \mathrm{L}$, respectively, indicating that the acute toxicity of DBP and DEHP to aquatic organisms was low, which was consistent with the previous research (Mayer and Sanders, 1973; Hu et al., 2012). In addition, the acute WQCs of DBP and DEHP are much higher than those specified in the environmental standards for surface water in China, indicating that their water quality standards can protect aquatic organisms from acute toxicity. Besides, the chronic WQC of DBP $(12.9 \mu \mathrm{g} / \mathrm{L})$ is higher than the water quality standard of DBP of $3 \mu \mathrm{g} / \mathrm{L}$, indicating that the water quality standard of DBP can also protect aquatic life from the long-term toxicity of DBP. However, the chronic WQC of DEHP $(1.0 \mu \mathrm{g} / \mathrm{L})$ is lower than the surface water quality standard of $8 \mu \mathrm{g} / \mathrm{L}$, indicating that the water quality standard of DEHP cannot provide scientific protection for aquatic organisms from the long-term toxicity of DEHP, which is consistent with the conclusion in the previous research (He et al., 2014). The chronic WQC of DBP derived in this study is close to that of Canada, while the chronic WQC of 
TABLE 2 | Exposure concentration of DBP and DEHP in six regions $(\mu \mathrm{g} / \mathrm{L})$.

\begin{tabular}{llccccc}
\hline Regions & Chemicals & min & Max & GM & SD & N \\
\hline Yangtze River basin & DBP & 0.013 & 60.7 & 0.83 & 8.96 & 93 \\
& DEHP & 0.01 & 92.4 & 1.03 & 14.87 & 98 \\
\hline Yellow River basin & DBP & 0.046 & 85.45 & 3.72 & 18.69 & 28 \\
& DEHP & 0.036 & 148.75 & 5.25 & 32.17 & 37 \\
\hline Huaine River basin & DBP & 0.03 & 133.7 & 1.19 & 19.87 & 45 \\
& DEHP & 0.03 & 68.81 & 1.37 & 11.94 & 32 \\
\hline Northern Region & DBP & 0.01 & 93.87 & 0.62 & 14.39 & 46 \\
& DEHP & 0.043 & 32 & 1.05 & 6.61 & 32 \\
\hline Southeast region & DBP & 0.03 & 118.8 & 1.84 & 40.63 & 97 \\
& DEHP & 0.087 & 99.02 & 1.92 & 18.31 & 87 \\
\hline Southwest region & DBP & 0.18 & 2.11 & 0.61 & 0.50 & 70 \\
& DEHP & 2 & 52.2 & 4.7 & 9.38 & 66
\end{tabular}

GM, geometric mean; SD, standard deviation; N, number.

DEHP is close to that of EU but lower than Canada. The differences between them are mainly due to the different biological sensitivity of different areas.

\section{Concentrations and Spatial Distributions of Dibutyl Phthalate and Bis (2-Ethlyhexyl) Phthalate in Surface Water}

The exposure data of DBP and DEHP were collected through literature review. The results show that the concentrations of DBP and DEHP in surface water in China are not detected (nd)-
TABLE 3 | Exposure concentration of DBP and DEHP in foreign countries $(\mu \mathrm{g} / \mathrm{L})$.

\begin{tabular}{lccl} 
Locations & DBP & DEHP & \multicolumn{1}{c}{ References } \\
\hline Kaveri River, India & nd-0.664 & nd-1.4 & Selvaraj et al. (2014) \\
Lake Pontchartrain, United States & nd-5.9 & nd-12 & Liu et al. (2013) \\
Epe and Lagos Lagoons, Nigeria & 0.13 & 0.18 & Adeogun et al. (2015) \\
Asan Lake, Korea & nd-6.78 & - & Lee et al. (2019) \\
Rieti district, Italy & - & 4.3 & Vitali (1997) \\
Berlin, Germany & - & 2.27 & Fromme et al. (2002) \\
Klang River basin, Malaysia & - & 16.6 & Tan (1995)
\end{tabular}

$133.7 \mu \mathrm{g} / \mathrm{L}$ and nd-148.75 $\mu \mathrm{g} / \mathrm{L}$, respectively (Suppplementary Table 5).

In order to analyze and evaluate the risk levels of DBP and DEHP in different regions of China, the exposure data of DBP and DEHP were divided into six regions and are summarized in Table 2. The concentration ranges of DBP in the Yangtze River basin, Yellow River basin, Huaihe River basin, Northern region, Southeastern region, and Southwest region are 0.013 to $60.7 \mu \mathrm{g} / \mathrm{L}$, 0.046 to $85.45 \mu \mathrm{g} / \mathrm{L}, 0.03$ to $133.7 \mu \mathrm{g} / \mathrm{L}, 0.01$ to $93.87 \mu \mathrm{g} / \mathrm{L}, 0.03$ to $118.8 \mu \mathrm{g} / \mathrm{L}$, and 0.18 to $2.11 \mu \mathrm{g} / \mathrm{L}$, respectively. While the concentration ranges of DEHP in these six regions are 0.01 to $92.4 \mu \mathrm{g} / \mathrm{L}, 0.036$ to $148.75 \mu \mathrm{g} / \mathrm{L}, 0.03$ to $68.81 \mu \mathrm{g} / \mathrm{L}, 0.043$ to $32 \mu \mathrm{g} /$ $\mathrm{L}, 0.087$ to $99.02 \mu \mathrm{g} / \mathrm{L}$, and 2 to $52.2 \mu \mathrm{g} / \mathrm{L}$, respectively. It can be seen from Table 2 that average concentrations of DEHP in all of the six regions are higher than those of DBP.

The concentrations of DBP and DEHP in several regions abroad are summarized based on the reported literature (Table 3). The results showed that the concentrations of DBP and DEHP in these regions ranged from nd- $16.6 \mu \mathrm{g} / \mathrm{L}$, which was lower than that in China. It shows that the pollution of DBP and

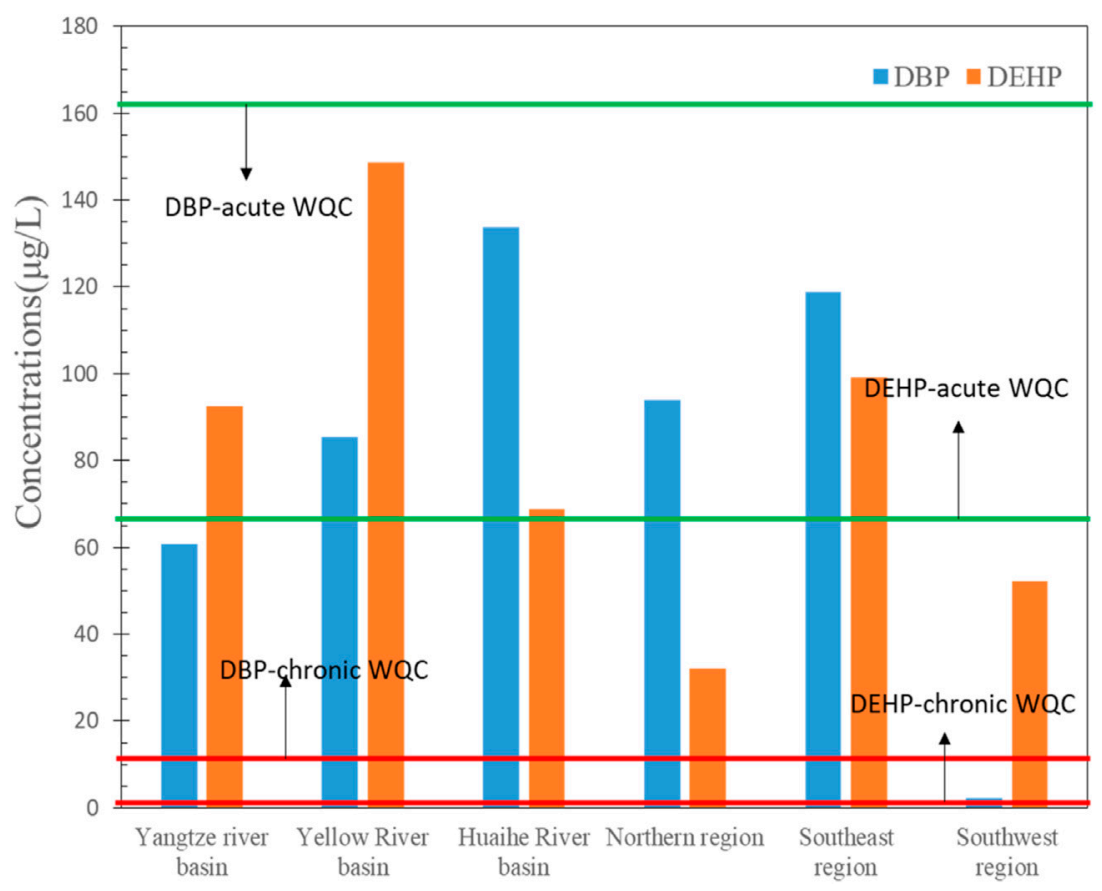

FIGURE 3 | Distributions of DBP and DEHP in six regions in China. 

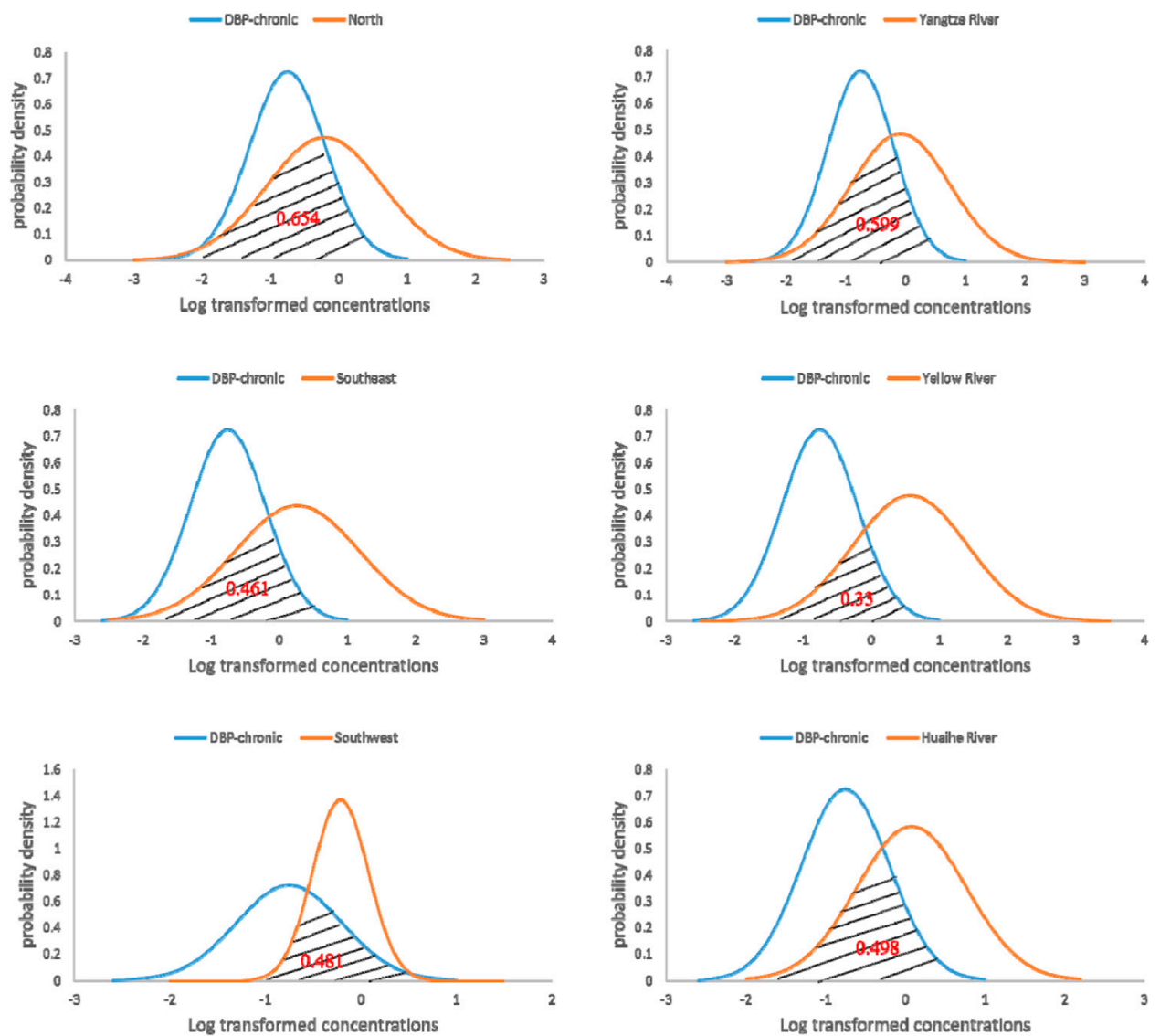

FIGURE 4 | Risk assessment of DBP in six regions of China.

DEHP in Chinese surface water is more serious, and more attention needs to be paid to management of PAEs pollution.

\section{Ecological Risk Assessment of Dibutyl Phthalate and Bis (2-Ethlyhexyl) Phthalate in Surface Water in China Risk Assessment by Hazard Quotients}

According to Table 2, the concentrations of DBP and DEHP in surface water in China range from 0.01 to $133.7 \mu \mathrm{g} / \mathrm{L}$ and from 0.01 to $148.75 \mu \mathrm{g} / \mathrm{L}$, respectively. The ecological risk of DBP and DEHP in six regions in China was assessed by HQ comparing the exposure concentrations and WQCs derived in this study.

The acute and chronic WQCs of DBP derived in this study are 162.9 and $12.9 \mu \mathrm{g} / \mathrm{L}$, respectively. It can be seen from Figure 3 that the maximum concentrations of DBP in six regions in China are lower than the acute WQC, indicating that the DBP in surface water environment will not cause acute toxicity effect on aquatic organisms. However, all the maximum concentrations of DBP in these regions far exceeded the chronic WQC for DBP, indicating that DBP levels may have caused chronic toxicity effects on aquatic organisms. Therefore, it is necessary to strengthen the environmental management of DBP and take measures to reduce the content of DBP to ensure the health and safety of water ecology in China.
The acute and chronic WQCs of DEHP derived in this study are 71.8 and $1.0 \mu \mathrm{g} / \mathrm{L}$, respectively. It can be seen from Figure 3 that maximum concentrations of DEHP in two regions are lower than the acute WQC, with four regions exceeding the acute WQC, indicating that the acute ecological risk of DEHP exists and need to be paid attention. Besides, the DEHP concentrations in all these six regions far exceeds the chronic WQC, which indicates that the chronic risk of DEHP is at relatively high level, which indicate that control measures should be taken to prevent the risk.

It could be concluded that the ecological risks of DBP and DEHP in surface water environment in China is at a high level, and it is necessary to further strengthen environmental management.

\section{Risk Assessment by Probabilistic Approaches}

As shown in Table 2, the exposure data of DBP and DEHP were divided into six regions and the ecological risk levels were evaluated using probabilistic approaches. As described before, the probability density distribution curves of both logtransformed toxicity data and log-transformed exposure data were plotted on the same axes, and the overlap area between the exposure and effect curves indicates the risk probability.

The chronic risk assessment results of DBP in six regions of Chinese surface water are shown in Figure 4. The overlapping areas calculated for the Yangtze River, Yellow River, Huai River, 

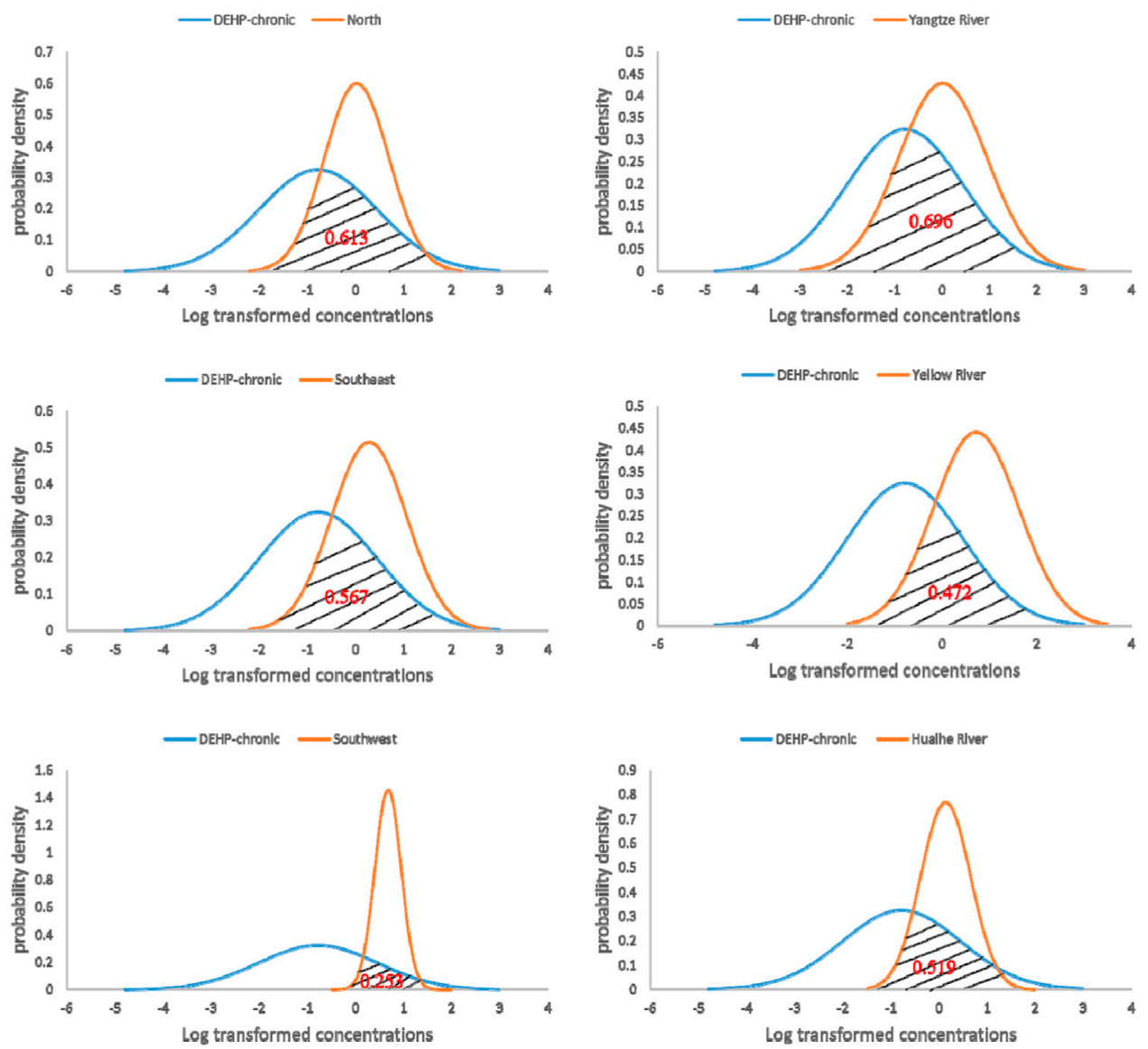

FIGURE $\mathbf{5}$ | Risk assessment of DEHP in six regions of China.

north, southeast, and southwest were $0.599,0.33,0.498,0.654$, 0.461 , and 0.481 , respectively. Risk probability order of these six regions is north $>$ Yangtze River $>$ Huai River $>$ southwest $>$ southeast $>$ Yellow River, indicating that the probability of chronic toxicity risk of DBP in surface water of northern region is the highest, while that of DBP in the Yellow River basin is the lowest.

The chronic risk assessment results of DEHP in six regions of Chinese surface water are shown in Figure 5. The overlapping areas calculated for the Yangtze River, Yellow River, Huaihe River, north, southeast, and southwest were 0.696, 0.472, 0.519, $0.613,0.567$, and 0.253 , respectively. Risk probability order of these six regions is Yangtze River $>$ north $>$ southeast $>$ Huai River $>$ Yellow River $>$ southwest, indicating that the probability of chronic toxicity risk of DEHP in surface water of the Yangtze River is the highest, while that of DEHP in the southeast is the lowest. For both DBP and DEHP, it can be concluded that the chronic risk probability in the Yangtze River and north of Chinese surface water are relatively higher than in other regions. This result is consistent with the possible high risk level of DBP and DEHP in the Yangtze River (Guo et al., 2020), indicating the distribution of PAEs are related to the degree of industrialization and the intensity of human activities (Shen et al., 2010; Huang et al., 2020). While the chronic risk probability in Yellow River and southwest of Chinese surface water are relatively lower, the results show that DBP and DEHP in the Yangtze River basin and the northern region have high ecological risks, which may cause adverse effects on aquatic organisms. Therefore, it is necessary to pay attention to and take measures to protect water ecological security.

\section{CONCLUSION}

This study provides an overview of toxicity data and exposure data of DBP and DEHP in surface water from China based on which the WQCs of DBP and DEHP for protection of aquatic life were derived and the ecological risk of them was evaluated. The following conclusions can be drawn. 1) The acute and chronic WQCs of DBP in Chinese surface water are 162.9 and $12.9 \mu \mathrm{g} / \mathrm{L}$, respectively. The acute and chronic WQCs of DEHP in Chinese surface water are 71.8 and $1.0 \mu \mathrm{g} / \mathrm{L}$, respectively. 2) In Chinese surface water, the acute ecological risks of DBP and DEHP are low and these two pollutants would not cause acute effects on aquatic organisms. While the chronic ecological risks of DBP and DEHP are generally higher. In some regions, the concentrations of DBP and DEHP seriously exceed the chronic WQCs, which might 
cause obvious ecological risk. So it is necessary to take control measures to reduce the DBP and DEHP concentrations and strengthen their environmental management. 3) Risk probability order of DBP in these six regions is north > Yangtze River $>$ Huaihe River $>$ southwest $>$ southeast $>$ Yellow River and the risk probability order of DEHP is Yangtze River $>$ north $>$ southeast $>$ Huaihe River $>$ Yellow River $>$ southwest. For both DBP and DEHP, it can be concluded that the chronic risk probability in the Yangtze River and north of Chinese surface water are relatively higher than in other regions. While the chronic risk probability in Yellow River and southwest of Chinese surface water are relatively lower. The results would provide technical support for the environmental management of PAEs in China.

\section{DATA AVAILABILITY STATEMENT}

The original contributions presented in the study are included in the article/Supplementary Material, and further inquiries can be directed to the corresponding author.

\section{REFERENCES}

Abdel Daiem, M. M., Rivera-Utrilla, J., Ocampo-Pérez, R., Méndez-Díaz, J. D., and Sánchez-Polo, M. (2012). Environmental Impact of Phthalic Acid Esters and Their Removal from Water and Sediments by Different Technologies - A Review. J. Environ. Manage. 109, 164-178. doi:10.1016/ j.jenvman.2012.05.014

Adeogun, A. O., Ibor, O. R., Omogbemi, E. D., Chukwuka, A. V., Adegbola, R. A., Adewuyi, G. A., et al. (2015). Environmental Occurrence and Biota Concentration of Phthalate Esters in Epe and Lagos Lagoons, Nigeria. Mar. Environ. Res. 108, 24-32. doi:10.1016/j.marenvres.2015.04.002

Cao, L., Zhang, C.-S., Chen, Q.-L., and Wei, W. (2018). Progress in the Study of Environmental Pollution and Ecological Behavior and Toxicological Effects of Phthalate Ester. Asian J. Ecotoxicol. 13 (2), 34-46. (in Chinese).

CCME (2021). Canadian Water Quality Guidelines for the Protection of Aquatic Life. Canadian Council of Ministers of the Environment. Available at: https:// ccme.ca/en/results/169,170/ch/1,2,3,4,5.

Chen, H., Mao, W., Shen, Y., Feng, W., Mao, G., Zhao, T., et al. (2019). Distribution, Source, and Environmental Risk Assessment of Phthalate Esters (PAEs) in Water, Suspended Particulate Matter, and Sediment of a Typical Yangtze River Delta City, China. Environ. Sci. Pollut. Res. 26, 24609-24619. doi:10.1007/s11356-019-05259-y

Chi, J. (2009). Phthalate Acid Esters in Potamogeton Crispus L. From Haihe River, China. Chemosphere 77 (1), 48-52. doi:10.1016/j.chemosphere.2009.05.043

Defoe, D. L., Holcombe, G. W., Hammermeister, D. E., and Biesinger, K. E. (1990). Solubility and Toxicity of Eight Phthalate Esters to Four Aquatic Organisms. Environ. Toxicol. Chem. 9 (5), 623-636. doi:10.1002/etc.5620090509

EU (2013). Directive 2013/39/EU of the European Parliament and of the council of 12 August 2013 Amending Directives 2000/60/EC and 2008/105/EC as Regards Priority Substances in the Field of Water Policy [R].

Fromme, H., Küchler, T., Otto, T., Pilz, K., Müller, J., and Wenzel, A. (2002). Occurrence of Phthalates and Bisphenol A and F in the Environment. Water Res. 36 (6), 1429-1438. doi:10.1016/s0043-1354(01)00367-0

Gao, X., Li, J., Wang, X., Zhou, J., Fan, B., Li, W., et al. (2019). Exposure and Ecological Risk of Phthalate Esters in the Taihu Lake basin, China. Ecotoxicology Environ. Saf. 171, 564-570. doi:10.1016/j.ecoenv.2019.01.001

Giribabu, N., and Reddy, P. S. (2016). Protection of Male Reproductive Toxicity in Rats Exposed to Di-n-butyl Phthalate during Embryonic Development by Testosterone. Biomed. Pharmacother. 87, 355-365. doi:10.1016/ j.biopha.2016.12.106

\section{AUTHOR CONTRIBUTIONS}

FS: conceptualization, methodology, and software. HS: data curation and writing-original draft preparation. YT and DS: investigation. YW: supervision. JY: software and validation. HL: writing-reviewing and editing.

\section{FUNDING}

This work was supported by the National Water Pollution Control and Management Technology Major Projects of China (No. 2018ZX07208-001) and National Natural Science Foundation of China (No.41907306).

\section{SUPPLEMENTARY MATERIAL}

The Supplementary Material for this article can be found online at: https://www.frontiersin.org/articles/10.3389/fenvs.2021.710125/ full\#supplementary-material

Guo, Y.-Y., Yang, L.-H., Zhou, B.-S., Ni, C.-H., and Li, Y.-F. (2020). Contaminated Level and Risk Assessment of Paes in the Upper Reaches of the Yangtze River. Acta Hydrobiol. Sin. 1-7. , 2020 (In Chinese).

Guo, Z. S., Jian, C., Cai, S.-T., Zhang, X.-L., and Zhu, M.-J. (2019). The Research of the Phthalate Ester Pollution in the Three Gorges Region in Chongqing after the Water Storage Period. China Resour. Compr. Util. 37 (02), 11-16. (In Chinese).

He, W., Qin, N., Kong, X.-Z., Liu, W.-X., He, Q.-S., Wang, Q.-M., et al. (2014). Water Quality Benchmarking (WQB) and Priority Control Screening (PCS) of Persistent Toxic Substances (PTSs) in China: Necessity, Method and a Case Study. Sci. Total Environ. 472, 1108-1120. doi:10.1016/j.scitotenv.2013.11.119

He, X.-T., Li, X., Yang, Y.-T., Li, K.-B., Li, G.-Y., and Nie, X.-P. (2010). Effects of Combined Toxicity of Phthalic Acid Esters on Zebrafish Embryonic Development. Acta Sci. Nat. Univ. Sunyatseni. 49 (05), 101-106. (In Chinese).

Howdeshell, K. L., Wilson, V. S., Furr, J., Lambright, C. R., Rider, C. V., Blystone, C. R., et al. (2008). A Mixture of Five Phthalate Esters Inhibits Fetal Testicular Testosterone Production in the Sprague-Dawley Rat in a Cumulative, DoseAdditive Manner. Toxicol. Sci. 105 (1), 153-165. doi:10.1093/toxsci/kfn077

Hu, X.-B., Wang, J.-N., Xu, Z.-C., and Zhang, X.-Y. (2012). Assessing Aquatic Ecological Risk of DEHP by Species Sensitivity Distributions. Ecol. Environ. Sci. 21 (06), 1082-1087. (In Chinese).

Huang, P.-P., Wang, C.-C., Qiu, C.-S., Sun, L.-P., Hu, S.-K., and Zhang, Y.-F. (2020). Occurrence, Environmental Risk and Water Quality Standard of PAEs in Water Environment. Environ. Eng. 38 (5), 23-29. (in Chinese).

Jia, Z. (2013). Ecological Toxicology Effects of Environmental Hormones to Aquatic Organisms. Beijing: Beijing Forestry University. (In Chinese).

Lee, Y.-M., Lee, J.-E., Choe, W., Kim, T., Lee, J.-Y., Kho, Y., et al. (2019). Distribution of Phthalate Esters in Air, Water, Sediments, and Fish in the Asan Lake of Korea. Environ. Int. 126, 635-643. doi:10.1016/ j.envint.2019.02.059

Li, W.-Y., Xiong, L., Liu, R., Jiang, Y., Hu, Q.-Q., and Wang, L.-M. (2007). Effects of DBP on Physiological and Biochemistr Ical Character Istics of Brachydanio Rerio [J]. Asian J. Ecotoxicol. 2 (01), 117-122. (In Chinese).

Liao, C.-X., Zhao, Y.-Z., Wang, S., Ou, M.-Z., and Zhang, Q.-H. (2017). Assessment of Acute Toxicity of DBP and DEHP on Gobiocypris Rarus. Chem. Sci. 35 (01), 90-93. (In Chinese).

Liu, H., Liang, H., Liang, Y., Zhang, D., Wang, C., Cai, H., et al. (2010). Distribution of Phthalate Esters in Alluvial Sediment: A Case Study at JiangHan Plain, Central China. Chemosphere. 78 (4), 382-388. doi:10.1016/j.chemosphere.2009.11.009

Liu, P., Tian, T., Barreto, J., and Chou, J. (2013). Assessment and Analysis of Phthalate Esters, in Lake Pontchartrain, by SPME Combining with GC-MS. Environ. Technol. 34 (4), 453-462. doi:10.1080/09593330.2012.698653 
Lyche, J. L., Gutleb, A. C., Bergman, Å., Eriksen, G. S., Murk, A. J., Ropstad, E., et al. (2009). Reproductive and Developmental Toxicity of Phthalates. J. Toxicol. Environ. Health B. 12 (4), 225-249. doi:10.1080/10937400903094091

Mayer, F. L., and Sanders, H. O. (1973). Toxicology of Phthalic Acid Esters in Aquatic Organisms. Environ. Health Perspect. 3, 153-157. doi:10.1289/ ehp.7303153

Pei, X. Q., Song, M., Guo, M., Mo, F. F., and Shen, X. Y. (2013). Concentration and Risk Assessment of Phthalates Present in Indoor Air from Newly Decorated Apartments. Atmos. Environ. 68, 17-23. doi:10.1016/j.atmosenv.2012.11.039

Qin, J.-F., Chen, H.-G., Cai, W.-G., Yang, T., and Jiao, X.-P. (2011). The Change of Biochemical Indexes in Different Tissue of Crimson Snapper (Lutjanus Erythropterus) Exposed to Di-(2-ethylhexyl)Phthalate(DEHP). J. Agroenviron. Sci. 30 (03), 409-415. (In Chinese).

Selvaraj, K. K., Sundaramoorthy, G., Ravichandran, P. K., Girijan, G. K., Sampath, S., and Ramaswamy, B. R. (2014). Phthalate Esters in Water and Sediments of the Kaveri River, India: Environmental Levels and Ecotoxicological Evaluations. Environ. Geochem. Health. 37 (1), 83-96. doi:10.1007/s10653-014-9632-5

Sha, Y.-J., Xia, X.-H., and Xiao, X.-Q. (2006). Distribution Characteristics of Phthalates in the Middle and Lower Reaches of the Yellow River. China Environ. Sci. 26 (01), 120-124. (In Chinese).

Shen, Y.-Y., Xu, X., Yin, X.-Y., Wang, M., Zhang, N.-P., Wu, S.-Y., et al. (2010). Determination and Distribution Features of Phthalate Esters in Xuanwu Lake. J. Southeast. Univ. (Natural Ccience Edition).v 40 (6), 1337-1341. (In Chinese).

Shi, W., Zhang, F.-X., Hu, G.-J., Hao, Y.-Q., Zhang, X.-W., Liu, H.-L., et al. (2012). Thyroid Hormone Disrupting Activities Associated with Phthalate Esters in Water Sources from Yangtze River Delta. Environ. Int. 42, 117-123. doi:10.1016/j.envint.2011.05.013

Solomon, K., Giesy, J., and Jones, P. (2000). Probabilistic Risk Assessment of Agrochemicals in the Environment. Crop Prot. 19 (8), 8-10. doi:10.1016/s02612194(00)00086-7

Song, X.-Y., Cui, X.-W., Li, J.-K., Guo, P., and Wei, J.-B. (2016). Research Advances in Soil Ecotoxicology of Phthalic Acid Esters (PAEs) Exposure. Ecol. Environ. Sci. 25 (11), 1885-1890. (In Chinese).

Sun, C.-Z., Li, F.-Y., Tu, H.-F., Jia, F.-L., and Li, F.-M. (2016). Review on the Impact of Phthalate Esters on Aquatic Food Chain. Asian J. Ecotox. 11 (6), 12-24. (in Chinese).

Tan, G. H. (1995). Residue Levels of Phthalate Esters in Water and Sediment Samples from the Klang River basin. Bull. Environ. Contam. Toxicol. 54 (2), 171. doi:10.1007/bf00197427

USEPA (1980). Ambient Water Quality Criteria for Phthalate Esters. EPA-440/5-80-067.

USEPA (2012). Phthalates Action Plan. Washington DC: U. S. Environmental Protection Agency.

USEPA (1997). Special Report on Environmental Endocrine Disruption: An Effects Assessment and Analysis EPA/630/R-96/012. Washington DC: U. S. Environmental Protection Agency.
Vitali, M. (1997). Phthalate Esters in Freshwaters as Markers of Contamination Sources-Aa Site Study in Italy. Environ. Int. 23 (3), 337-347. doi:10.1016/s01604120(97)00035-4

Wang, J., Luo, Y., Teng, Y., Ma, W., Christie, P., and Li, Z. (2013). Soil Contamination by Phthalate Esters in Chinese Intensive Vegetable Production Systems with Different Modes of Use of Plastic Film. Environ. Pollut. 180, 265-273. doi:10.1016/j.envpol.2013.05.036

Wang, X.-N., Zhang, Y., Wang, W.-H., Yu, R.-Z., Liu, Z.-T., Cao, Y., et al. (2017). Environmental Pollution and Toxicity of DEHP. Asian J. Ecotoxicol. 12 (03), 135-150. (In Chinese).

Wu, F.-C., Meng, W., Zhao, X.-L., Li, H., Zhang, R.-Q., Cao, Y.-J., et al. (2010). China Embarking on Development of its Own National Water Quality Criteria System. Environ. Sci. Technol. 44 (21), 7992-7993. doi:10.1021/es1029365

Zhai, W.-H., Huang, Z.-G., Chen, L., Feng, C., Li, B., and Li, T.-S. (2014). Thyroid Endocrine Disruption in Zebrafish Larvae after Exposure to Mono-(2Ethylhexyl) Phthalate (MEHP). PLoS ONE 9 (3), e92465. doi:10.1371/ journal.pone.0092465

Zhang, J.-J., and Shu, W.-Q. (2005). [Progress in Phthalate Ester Toxicity in the Female Reproductive System]. Wei Sheng Yan Jiu. 34 (4), 496-498. (In Chinese).

Zhang, W.-Z., Lai, Z.-N., Zhao, L.-N., Wang, C., Gao, Y., and Yang, W.-L. (2015). Acute Toxicity Study of Phthalate Esters (PAEs) on the Magalobrame Tarminalis. J. Biol. 32 (01), 26-29. (In Chinese).

Zhao, C.-F., Diao, X.-P., Xie, J., Song, Q.-Q., Zheng, P.-F., Wang, H.-H., et al. (2014). Effects of Diethylhexyl Phthalate on Haemocyte Immune Functions and Oxidative Stress in Pinctada Martensi. Asian J. Ecotoxicol. 9 (2), 375-381. (In Chinese).

Conflict of Interest: The authors declare that the research was conducted in the absence of any commercial or financial relationships that could be construed as a potential conflict of interest.

Publisher's Note: All claims expressed in this article are solely those of the authors and do not necessarily represent those of their affiliated organizations, or those of the publisher, the editors and the reviewers. Any product that may be evaluated in this article, or claim that may be made by its manufacturer, is not guaranteed or endorsed by the publisher.

Copyright (c) 2021 Sun, Tao, Shi, Yang, Li, Wei and Su. This is an open-access article distributed under the terms of the Creative Commons Attribution License (CC BY). The use, distribution or reproduction in other forums is permitted, provided the original author(s) and the copyright owner(s) are credited and that the original publication in this journal is cited, in accordance with accepted academic practice. No use, distribution or reproduction is permitted which does not comply with these terms. 